\title{
Review on bioethanol as alternative fuel for spark ignition engines
}

\author{
Saravana Kannan Thangavelu ${ }^{\mathrm{a}, \mathrm{c}}$, Abu Saleh Ahmed ${ }^{\mathrm{b}}$, Farid Nasir Ani ${ }^{\mathrm{a}, *}$ \\ a Department of Thermo Fluids, Faculty of Mechanical Engineering, Universiti Teknologi Malaysia, UTM 81310 Skudai, Johor D.T., Malaysia \\ ${ }^{\mathrm{b}}$ Department of Mechanical and Manufacturing Engineering, Faculty of Engineering, Universiti Malaysia Sarawak, Sarawak, Malaysia \\ ${ }^{\mathrm{c}}$ Faculty of Engineering, Computing and Science, Swinburne University of Technology, 93350 Kuching, Sarawak, Malaysia
}

\section{A R T I C L E I N F O}

\section{Article history:}

Received 6 August 2014

Received in revised form

29 November 2015

Accepted 30 November 2015

Available online 24 December 2015

\section{Keywords:}

Spark ignition engine

Bioethanol

Production

Combustion

Performance

Emission

\begin{abstract}
A B S T R A C T
Bioethanol fuel obtained from biomass and bioenergy crops has been proclaimed as one of the feasible alternative to gasoline fuel, as it is considered to be clean, renewable and green. In this review, the bioethanol production techniques from different lignocellulosic biomass, and its potential ethanol yield are studied. Moreover, this paper has reviewed the effects of bioethanol fuel blends on spark ignition engine combustion characteristics (i.e. cylinder pressure, cylinder temperature, flame speed, combustion efficiency, combustion duration, heat release rate, knocking and cold start); engine performance parameters (i.e. torque, brake power, brake specific fuel consumption, brake mean effective pressure, brake thermal efficiency and volumetric efficiency); and emission characteristics (i.e. carbon monoxide, oxides of nitrogen, carbon dioxide, unburned hydrocarbon and other unregulated emissions).

Recently, many researchers produced bioethanol from herbaceous, industrial and municipal solid wastes (MSW) instead of agriculture and woody biomass. Most of the engine test results showed a remarkable improvement in engine performance and enhanced combustion characteristics for bioethanol fuel. In addition, the carbon monoxide and unburned hydrocarbon emissions decreased. Conversely, carbon dioxide and oxides of nitrogen emissions were not significantly reduced. Furthermore, there was no significant reduction of unregulated emissions, such as aromatics, acetaldehyde, and carbonyls.
\end{abstract}

(c) 2015 Published by Elsevier Ltd.

\section{Contents}

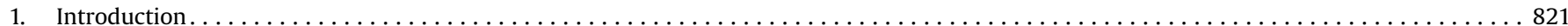

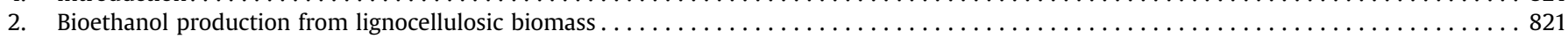

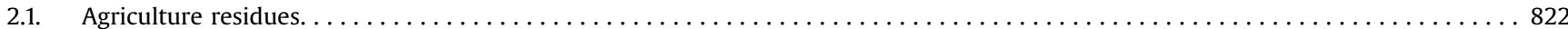

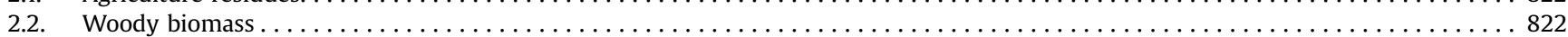

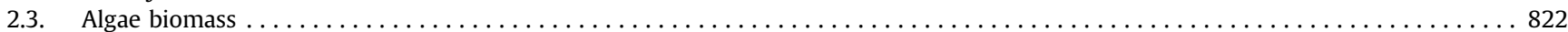

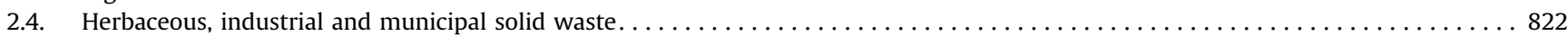

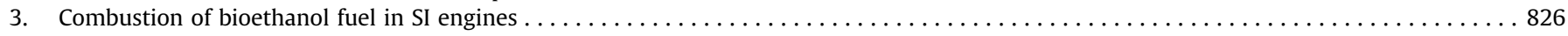

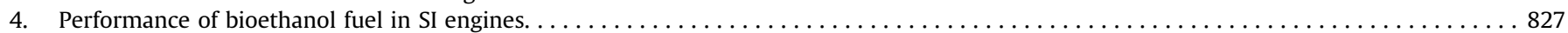

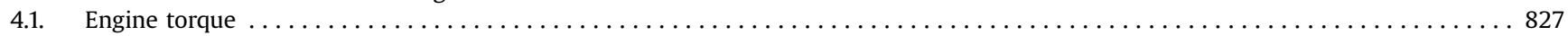

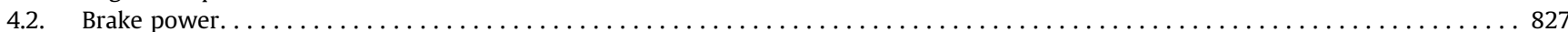

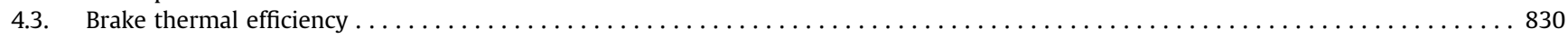

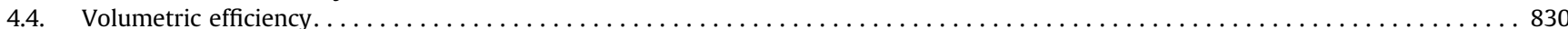

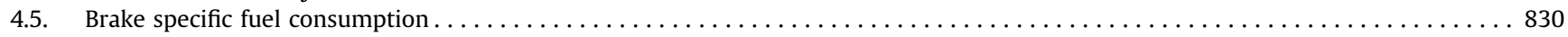

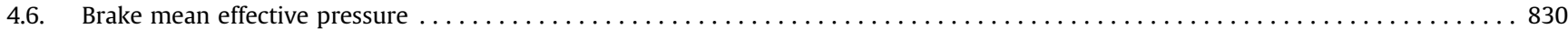

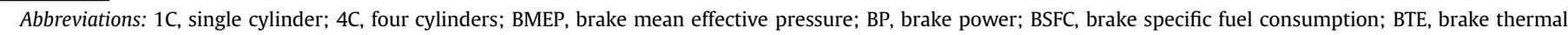

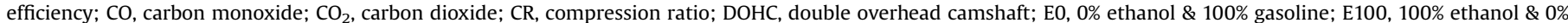

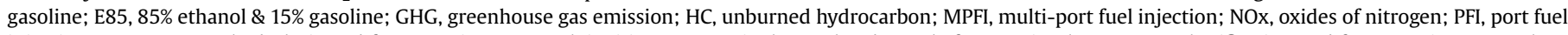

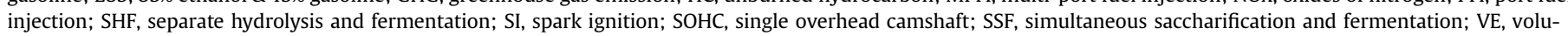
metric efficiency; WOT, wide open throttle

* Corresponding author. Tel.: +60 7 5534715; fax: +60 75566159.

E-mail address: farid@mail.fkm.utm.my (F.N. Ani). 


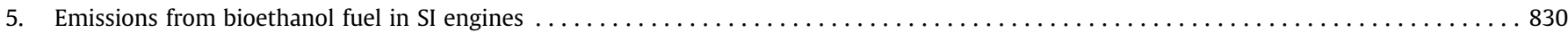

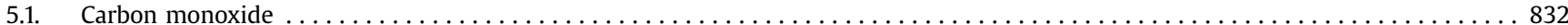

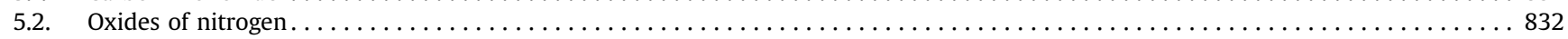

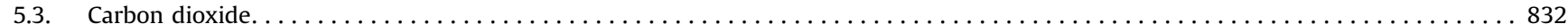

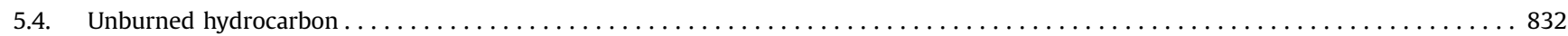

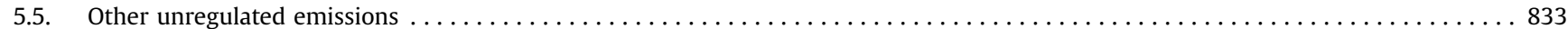

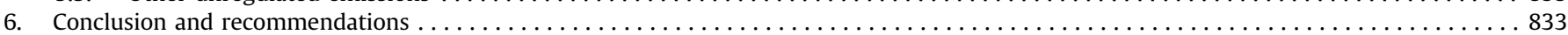

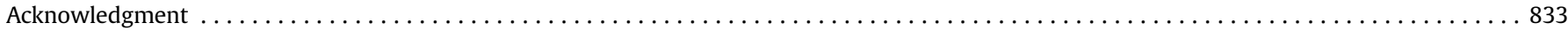

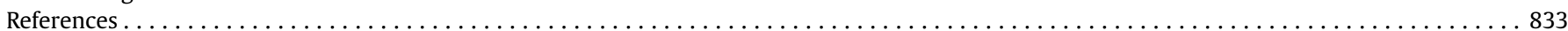

\section{Introduction}

The increasing demands of petroleum-based fuels due to rapid development of industry and automotive society coupled with the environmental pollution issues have inspired the efforts on exploring alternative fuels for internal combustion engines in past decades $[1,2]$. A greater significance has been placed to find clean and sustainable alternative fuel to meet environmental needs [3]. The most eminent alternative fuels for replacing petroleum-based fuels in internal combustion engines are biofuels (biodiesel and bioethanol) [4]. Bioethanol or fuel ethanol is one of the most important biofuels produced from bioenergy crops and biomass [5]. It is considered as clean, renewable and green combustible fuel alternative to gasoline because of its high octane number, high heat of vaporization, and low vapor pressure. Furthermore, ethanol is easily miscible and used as oxygenated portion in gasoline for cleaner emission [6,7]. Bioethanol enjoys a better position than biodiesel due to greater environmental sustainability of raw materials it is obtained from, lower greenhouse gas (GHG) emissions, lower production cost and a more favorable future evolution [1-5]. The purpose of this review is to discuss the current technologies in bioethanol fuel production, and its effects on performance and emissions of spark ignition (SI) engines.

Bioethanol has the potential to replace gasoline in internal combustion engines; however, the cost of bioethanol production is high compared to petroleum-based fossil fuels [7,20]. Currently, large scale fuel ethanol production is mainly based on sugar containing raw materials (i.e. sugarcane) and starch grains (i.e. corn, wheat and cassava) which are not desirable due to their food and feed value [8]. Lignocellulosic biomasses such as agriculture residues, woody biomass, and algae, industrial and municipal solid waste are the potential resources for bioethanol production worldwide [9]. They are not only renewable, but also low cost, abundant and sustainable. Rice straw, wheat straw, corn straw, and sugarcane bagasse are the major agricultural residues, which are suitable for large scale bioethanol production in terms of quantity of biomass available [10-11]. Moreover, starchy industrial biomasses such as waste from starch processing factories, potato food factories, and beverage and brewery factories are promising feedstock for high yield large scale production in tropical locations [12-14].

Bioethanol production from lignocellulosic biomass involves different steps of pretreatment, hydrolysis, fermentation and ethanol recovery $[15,19]$. Pretreatment is a crucial step to alter some structural characteristics of biomass which will increase the glucan and xylan accessibility for further hydrolysis process [16]. Different pretreatment techniques, such as physical, chemical, physico-chemical and biological have been developed for bioethanol production in past decade [15-18]. Acid or enzymatic hydrolysis of biomass is essential for generation of fermentable sugars which are then converted to ethanol by microbial biocatalyst through fermentation [19]. Even though the lignocellulosic biomass is renewable and abundant, the bioethanol fuel production from lignocellulosic biomass has not yet been commercialized in many countries [15]. The main obstacles in bioethanol production are high production cost and energy requirements [20]. Moreover, the lack of knowledge about production techniques and the effect of bioethanol on engine performance and emissions. Researchers studied the effects of fuel ethanol blended with gasoline in different SI engines and suggested that bioethanol can be used as alternative fuel for the vehicles equipped with SI engines [26-29].

There are many reviews reported in bioethanol production and its future perspectives [1-5,8-11,15-23,136-140]. Few of the reviews reported the suitability of alcohol fuel for internal combustion engines with more emphasis on diesel engines [24-27]. Recent review by Masum et al. [28] studied the effect of ethanol and gasoline blend on NOx emission in SI engine. The effects on fuel properties, fuel efficiency and emissions for blending ethanol and gasoline in SI engine were presented by Stein et al. [29]. However, a survey of literatures showed that there is no separate review on bioethanol fuel for SI engine which comprehensively described both bioethanol production technologies, and engine performance and emission studies.

This review is intended to discuss the recent studies on bioethanol production from different feedstock and its ethanol yield in the first section. Furthermore, the effects of bioethanol fuel blending to gasoline in SI engines including combustion, performance, and emission characteristics are discussed in the subsequent sections.

\section{Bioethanol production from lignocellulosic biomass}

Agriculture residues; herbaceous, industrial and municipal solid wastes (MSW); woody biomass; and algae are the major lignocellulosic biomass substances which contain cellulose, hemicellulose and lignin [8,9]. In addition, starch is also found in the composition of starchy biomass, such as cassava pulp, food waste and sago palm waste which are categories under MSW [8,12-14].

The first step in the bioethanol production is pretreatment which mainly includes physical treatment for biomass size reduction; and thermochemical processes for the disruption of unmanageable materials of the biomass to increase the substrate porosity with lignin redistribution [16-18]. The second step is hydrolysis process which depends on the effectiveness of the pretreatment operation. During hydrolysis, the released sugar polymers such as starch, cellulose and hemicellulose are hydrolyzed into free sugar monomers [19-21]. The third step is fermentation which is the conversion of available fermentable sugars into ethanol by microorganisms or biocatalyst $[10,15]$. Researches have established different techniques for bioethanol production from lignocellulosic biomass. A brief review of various studies between the years 2010 and 2014, on the bioethanol production 